\title{
Synthesis and characterization of ultra small PbS nanorods in sucrose ester microemulsion.
}

\begin{abstract}
$\mathrm{n}$ the present study, we report for the first time the synthesis of ultra small $\mathrm{PbS}$ nanorods in a non-ionic sugar based water-in-oil (w/o) microemulsion system using food grade sucrose ester as surfactant. $\mathrm{PbS}$ was formed by mixing lead nitrate and thioacetamide in the water core of the microemulsion system. The as-prepared $\mathrm{PbS}$ nanorods were characterized by $\mathrm{X}$ ray diffractometry (XRD), uv-visible absorption spectroscopy (UV-VIS), transmission electron microscopy (TEM) and X-ray photoelectron spectroscopy (XPS). The diameter of the $\mathrm{PbS}$ nanorods were found to be extremely small, which is in the range of $2.64 \mathrm{~nm}$ to 2.91 $\mathrm{nm}$ depending on reaction aging time. Spherical $\mathrm{PbS}$ nanoparticles were formed after $12 \mathrm{~h}$ and $\mathrm{PbS}$ nanorods were formed after more than 1 day of reaction aging time.
\end{abstract}

Keyword: Electron microscopy; Nanomaterials; Chalcogenides; Sucrose ester; Microemulsion. 